\title{
Methods of Conditioning Sustainable Growth Programs of Power Generating Companies
}

\author{
A P Garnov ${ }^{1, *}, O N$ Bykova $^{2}$ and $V M$ Repnikova $^{2}$ \\ ${ }^{1}$ Department of Industrial Economics, Plekhanov Russian University of Economics, 36 Stremyanny lane, Moscow, Russia \\ ${ }^{2}$ Department of Entrepreneurship and Logistics, Plekhanov Russian University of Economics, 36 Stremyanny lane, Moscow, Russia
}

\begin{abstract}
Purpose: to propose a program for the sustainable development of production complexes of the electric power industry, a distinctive feature that will be to increase production efficiency and preserve the environment.Findings: after conducting a scientific study, the authors obtained indicators for analyzing the effectiveness of the program, which were tested on the example of two territorial generating companies located in Buryatia and the Trans-Baikal Territory.Results: the proposed and tested program contains a number of advantages related to energy efficiency, preserving the environment, increasing the reliability and uninterrupted power supply.Value: the proposed program of the sustainable growth of power generating companies considering the adjustment of the production characteristics, the use of energy resources and the existing infrastructure, can become the basis for the power companies.
\end{abstract}

\section{Introduction}

Building a mechanism for the sustainable growth of power generation systems must be based on a set of effective actions aimed at maintaining such sustainable growth and environmental conservation. In this event, the sustainable growth should focus on the long-term period and the relationship between nature and society, business and the state [1].

The power generation systems shall sustainably grow in the following areas [2]:

- formation of mechanisms for enhancing the technological development;

- reducing inefficient spending;

- bringing the assets of power generation facilities in line with the power production output;

- strengthening fiscal control and the ability to find additional sources of funding;

- drawing up the highest priority problems facing the production complex;

- formation of targets, the achievement of which will be driven by formulation of strategy and enhancement of sustainable growth;

- conditioning its implementation;

- transformation of the managerial setup into the most customized form to facilitate the need for sustainable growth;

- calculating the necessary resources for sustainable growth;

- putting actions in place that are aimed at improving the level of growth and monitoring their implementation;

- development of an approximate model of sustainable and unsustainable growth;
- case study related to sustainable performance of the production sector and the development of prevention programs;

- formation of actions for permanent financial recovery of the production sector [3].

Articulation of issue:

The overriding principle to make the sustainable growth program happen is the innovation and science \& technology policy, which consists in creating a stable national innovation system in order to ensure the power generation sector with high-performance technologies. This principle requires the following solutions:

- advancement of fundamental science and applied research;

- innovation conditioning;

- creating a system of state backing and stimulation of power generation companies as part of innovation projects;

- using the opportunities of world practice.

The above may happen by means of:

- identifying and providing economic support for promising game-changing as well as scientific and engineering projects;

- providing financial resources of basic science aimed at searching for new technologies and designs;

- restoration of the innovation cycle;

- creating a forecasting system in the power industry;

- building targeted scientific, technical and innovative programs [4].

State regulation is advisable to concentrate on the following [5]:

1. Upgrade and creation of new power generating capacities inspired by large-scale technological renewal;

\footnotetext{
* Corresponding author: profgarnov@yandex.ru
} 
2. Reduction of costs and increase in equipment performance as a result of upgrading;

3. Reducing the trend of physical and moral depreciation of production assets;

4. Prevention of process upsets;

5. Ensuring the safe and reliable operation of power plants;

6. Stimulating the performance of small and medium-sized companies specializing in industry specifics (equipment sales, technology development, repairs and other activities);

7. Enhancing the performance of the equipment by improving its characteristics, perfecting the processes control [6].

\section{Results}

A program for the sustainable growth of power sector facilities will be developed based on the improvement of the production performance and preservation of the environment.

The first phase of the program is to make decisions by the top management on the need to take actions on how to make the sustainable growth enhanced. The consequences of such actions shall be regarded in the economic, social, environmental, scientific field followed by a comprehensive assessment of costs. In order to make the process of sustainable growth happen and assess the effectiveness of its use, it is meaningful to establish benchmarks and ensure control of their implementation. Company performance can serve as the benchmarks, for example, the company's profit, energy consumption, the number of accidents, the cost of repairing the primary production facilities, the number of sites put in service, as well as growth indicators, that is, everything that allows to qualitatively increase the indicators of the company and the process of their use [7].

The second phase consists of a comprehensive audit of the company. It shall identify key factors and determine the degree of their optimization. The result of the audit is a detailed in-house information analysis that allows describing the current state of the company and giving directions for making the sustainable growth happen [8].

The third phase results in formulation and introduction of a plan. If the in-house information analysis describes the current state of the company, the plan indicates the desired state, which characterizes [9]:

- design of sustainable growth systems;

- development analysis and evaluation;

- formulation and introduction of a plan;

- $\quad$ setting up complete and concerted efforts of plan implementation.

The possibility of managing the sustainable growth processes by changing strategic and tactical plans is also being investigated. The implementation plan for the sustainable growth mechanism is an effective tool for maximizing key indicators [10].
The fourth phase introduces strategic and operational plans to enhance the sustainable growth of the power production sector.

The program of how to put this phase into practice is as follows [11]:

1. Acquisition, processing and analysis of data on the state of the company and the external environment. Growth prospects;

2. Determining the combination of indicators to identify factors constraining the sustainable growth;

3. Fixing the expected value;

4. Evaluation of actual and desired indicators;

5. Reveal of internal and external factors that determine the actual value of the indicators and the influence of factors on them;

6. Formulation and introduction of an action plan with a detailed description of the mechanisms for their achievement;

7. Monitoring the implementation of the sustainable growth plan;

8. Performance evaluation. Conclusions and results of actions taken.

The sustainable growth program of the power sector should be formulated as a document referring to the targets and purpose of sustainable growth (table 1). With any challenge, the purpose should be changed and transformed under the new requirements of the power sector. The core targets are:

1. Enhancement of the efficiency of power plants and fuel resources use;

2. Increased investment attractiveness;

3. Design and introduction of the production facilities upgrade policy;

4. Optimization of existing retrofitting programs, etc

The first section of the program contains general information about the program and other data to indicate in this section.

The section "mission and purpose of the program" describes the activity of the company, and the purpose and mission of the program is formed following the opinions of experts, analysts, auditors and the management of the company [12].

The third section "information (analytical) base of the program" is based on collecting and conducting a series of study analyzes of the business and financial performance of an undertaking, which can be divided into the following phases[13]:

1. Building an expert panel consisting of a number of management and audit bodies of the company, heads of departments (branch offices), third-party experts and analysts, employees of government departments and major shareholders of the company (max. 50 persons) [14];

2. A comprehensive diagnosis of production facilities in place [15]:

- monitoring and evaluation of the current state of the equipment as well as costs and benefits of its further use;

- diagnostics and expert examination of the site;

- designing equipment upgrade stages;

- search for investment resources. 
Table 1. The content of the document called Sustainable Growth Program of Power Generating Company.

\begin{tabular}{|c|c|}
\hline Document sections & Content \\
\hline 1. General Provisions & $\begin{array}{l}\text { 1. Program precondition; } \\
\text { 2. Basic terms and definitions; } \\
\text { 3. Developers and persons in charge of program. }\end{array}$ \\
\hline 2. Program Purpose and Mission & $\begin{array}{l}\text { 1. Description of company profile; } \\
\text { 2. Design of program purpose; } \\
\text { 3. Design of program mission. }\end{array}$ \\
\hline $\begin{array}{c}\text { 3. Information (Analytical) Base of } \\
\text { Program }\end{array}$ & $\begin{array}{l}\text { 1. Company business analysis; } \\
\text { 2. Assessment of performance indicators; } \\
\text { 3. Analysis of existing issues; } \\
\text { 4. Company Threats. }\end{array}$ \\
\hline $\begin{array}{l}\text { 4. Forming sustainable growth obj- } \\
\text { ectives }\end{array}$ & $\begin{array}{l}\text { 1. Problem; } \\
\text { 2. Problem Description; } \\
\text { 3. Problem; } \\
\text { 4. Problem Description, etc. }\end{array}$ \\
\hline 5. Actions to ensure sustainable growth & $\begin{array}{l}\text { 1. Search for optimal solutions to the problem; } \\
\text { 2. Design of a project to address them; } \\
\text { 3. Implementation of the project. }\end{array}$ \\
\hline 6. Program Management & $\begin{array}{l}\text { 1. Appointment of persons exercising control over the implementation of } \\
\text { the program; } \\
\text { 2. Analysis of actions taken. }\end{array}$ \\
\hline
\end{tabular}

The equipment information base to put in place including the data: year of manufacture, a brief description of the equipment, data taken from the data sheet, the date of the first and last repair, the assessment of the expert panel on the state of the power equipment, a preliminary assessment of expenditures connected with the repair, the estimated service life, the date of the data entry and the date of the data correction.

Each member of the expert panel makes a list of threats facing the company. Each item in the list should rest on verified information by analyzing the financial and economic activities of the company, assessing the influence of external and internal factors, as well as on the existing problems.

3. The lists of threaten are taken to produce a general list of threats, to combine similar opinions and to form lists according to the following main types of threats:

- that have an effect on the gain in energy performance of the equipment and system;

- that affect the operation and ensure operational reliability and safety of the equipment;

- that affect environmental protection, safety of working environment and information support of the company.

4. The expert panel met to review these lists to produce a final list of threats. At the same meeting, 5 to 6 significant threats will be selected.

Section "formulation of problem related to sustainable growth". Each member of the expert panel forms 5 priority problems for ensuring sustainable growth with reference to recommended actions to eliminate threats. Further, the expert panel will accept and describe the essence of the problem, formulates recommendations for its solution.

The fifth section, "actions to ensure sustainable growth", consists in finding the best ways to solve the given problems, assesses the possibilities, analyzes alternative ways to solve them, and provides operational plans. The solution to each problem requires to provide a description as follows [16]:

- essence of problem;

- expected effect (economic, technological, organizational, etc.);

- lead time

- action;

- problem agenda.

Design of an investment project. This phase looks for investments and forecasts the amount that will be obtained by attracting investments, and based on the information received, projects are being developed to upgrade and modify the production facilities [17]. It is possible to attract investments by complete disclosure of information about the program. Thanks to this, the bank or credit institution has the opportunity to calculate the economic effect of the implemented program and make a decision on investing. In addition, the investor shall have the opportunity to design, adjust and manage the project.

Next comes the introduction of innovative and scientific \& technical developments. Here it is necessary to develop a broad innovation, scientific and technical update due to the introduction of domestic technologies, materials and equipment when interacting with other sectors of the economy. It is a good practice to strike two paths:

- the search for innovative models and scientific and technical developments, the purchase of new equipment from third-party organizations, and the opening of a platform for the search for new inventions. The main goal is to search for new designs that will improve energy efficiency, reliability and other technical and economic indicators of the equipment; 
Table 2. Program evaluation indicators.

\begin{tabular}{|l|c|c|c|c|}
\hline \multicolumn{1}{|c|}{ Indicator } & Indicators before & Expected effect & Indicators after & Result \\
\hline Specific reference fuel consumer & 8 & 3 & 5 & 0.6 \\
\hline Capacity factor & 7 & 4 & 5 & 0.8 \\
\hline Greenhouse gas emissions & 10 & 3 & 4 & 0.75 \\
\hline Leakage of hazardous substances & 9 & 2 & 2 & 1.0 \\
\hline Emissions of $\mathrm{SO}_{2}, \mathrm{NO}_{2}, \mathrm{CO}$ & 9 & 2 & 3 & 0.7 \\
\hline Waste disposal & 6 & 3 & 3 & 1.0 \\
\hline Water usage & 7 & 4 & 5 & 0.8 \\
\hline
\end{tabular}

- creation of a research and development center at the power generating company site with the involvement of specialists for the development of innovative equipment models. The center is a common platform for inventors and scientists who together develop more efficient pieces of equipment and introduce them into the production process. It implements actions aimed at new innovations and perfection of existing production and technical systems. It consists of scientists and experts who calculate the reality and effectiveness of certain ideas, innovations, carry out technical and economic calculations in order to identify the payback of innovation.

The last section, "program control," provides for building a control body that will monitor the performance of all functions and manages the implementation plan for sustainable growth activities. A system of indicators to international standards shall be introduced to control the implementation of the program. These indicators will provide strong interest to relevant groups. International agencies offer the following indicator system: greenhouse gas emissions, leakage of harmful substances, $\mathrm{SO}_{2}, \mathrm{NO}_{2}, \mathrm{CO}$ emissions, waste disposal, and water use. [10].

Table 2 lists indicators for analyzing the performance of program, which were tested on the example of two territorial power generating companies from Buryatia and Trans-Baikal Territory [18].

Having conducted a study of the effectiveness of the program in 2017-2018 years on the example of two generating companies, the authors came to the conclusion that prior to the implementation of the program, many indicators influencing the environmental situation in the region were at the maximum permissible limits. Having made suggestions for improving the program, we are seeing obvious improvements, of course, these indicators are not as optimistic as was stated in the expected effect, but in any case there is a positive trend. As a result, the task of energy efficiency, reliability and uninterrupted operation, reducing emissions of pollutants into the atmosphere was solved.

The result of the study was the following proposals, it is necessary to carry out:

- analysis of the level of deterioration of production assets;

- regulation of the basic provisions for updating production capacities;

- indicative planning based on various methods of forecasting and estimating the volume of production.
Comprehensive proposals were made on the need to develop a strategic concept for the use and development of the production complex of two generating companies located in Buryatia and the Trans-Baikal Territory. ; measures to exit enterprises from the state of crisis; development programs for the region's industrial complex for 4-5 years using the means to achieve them on the basis of business planning and innovative design.

\section{Summary}

The proposed program contains new elements in comparison with existing programs:

1. Engaging a wide variety of stakeholders in making a sustainable growth program.

2. Program executors are involved in its development thereby enhancing the efficiency of its implementation.

3. The program identifies three priority areas:

- $\quad$ efficient energy use;

- environmental protection;

- increase of reliability and fail-safe power supply.

4. Attraction of banks for implementation of the program to calculate its benefits as well as the ability to manage and develop the program.

5. The main challenges and ways to solve them are formed at the meeting of the expert panel, which eliminates the possibility of double interpretation and allows more efficient use of the existing potential of the company.

6. Creation of a platform at the power generating company dedicated to the search for new developments.

7. Indicators that meet international standards are used as an assessment of the program performance.

The implementation of the program should provide the following:

1. Enhancing the efficiency of power generation and creating a competitive advantage over other companies as a result of production upgrade and new capacities in operation, increasing the efficiency of using service and maintenance aids, carrying out routine repairs and maintenance of power facilities, reducing the scopes of unfinished construction and production costs;

2. Prompt and high-quality maintenance, repair and renovation of production facilities aimed at ensuring the reliability, trouble-free, safe operation of fixed production assets; 
3. Reducing emissions of pollutants to the atmosphere and increasing efficiency by game-changing technologies in the production of electric energy.

\section{References}

1. Current problems of power sector, collection of scientific and technical papers: dedicated to the 80th anniversary of prof. S V Khvatov, 312 (2018)

2. S. Borenstein, The Trouble with Electricity Markets (and Some Solutions). POWER Program of the University of California Energy Institute Berkley, 27 (2010)

3. P.C. Camp, Benchmarking. The Search of Industry Best Practice That Lead to Superior Performance, ASQC Industry Press, 61-63 (2009)

4. P.R. Cateora, International marketing, 64 (2011)

5. G.A. Charchill, Marketing Research, Technical Foundations, 123 (2011) 